\title{
Influence of alloying elements on the thermal behavior of NiTi shape memory alloys
}

\author{
Nicoleta-Monica Lohan ${ }^{1}$, Ștefan-Lucian Toma ${ }^{1}$, Mihai Popa ${ }^{1}$, Alin Marian Cazac ${ }^{1}$, and \\ Bogdan Pricop ${ }^{1 *}$ \\ 1"Gheorghe Asachi" Technical University of Iasi, 67 Dimitrie Mangeron Blv., Iasi 700050, Romania
}

\begin{abstract}
NiTi based shape memory alloys are one of the most intensely studied alloys from its class. Therefore, diverse commercial applications have been developed due to certain properties such as: shape memory effect, superelasticity and corrosion resistance. Currently, the main applications of NiTi alloys are automotive manufacturing and aerospace actuators, biomedical devices or pipe couplings. In recent years, NiTi shape memory alloys have been alloyed with a third element in order to improve the above-mentioned properties. In order to investigate the influence of the alloying elements on the thermal behavior of NiTi alloys, the addition of the third alloying element $(\mathrm{Ta}$ and $\mathrm{Nb}$ ) is under investigation in the present study. The thermal behavior of the three alloys (NiTi, NiTiNb and NiTiTa) was studied by differential scanning calorimetry. Following the experiments, it was observed that the addition of the third alloying element influences the critical transformation temperatures.
\end{abstract}

\section{Introduction}

Shape memory alloys (SMAs) are a group of materials that are part of the "smart materials" category. SMAs have the ability to return to a pre-deformed shape when subjected to thermal or mechanical procedures or even magnetic stimuli. The SMAs have various properties such as: ductility [1], strength [2], good biocompatibility [3], specific functional properties like shape memory effect [4], pseudeoelasticity [5] and superelasticity (SE) [6]. Due to these properties, they have a myriad of applications in many fields: biomedical [7], construction [8, 9], aerospace [10], automobile [11, 12], robotics [13], and even extraterrestrial roving missions [14]. Several examples of SMAs systems include: Ni-Ti based, $\mathrm{Cu}$ based (Cu-Zn-Al and $\mathrm{Cu}-\mathrm{Al}-\mathrm{Ni}$,) and Fe based (Fe-Mn-Si, Fe-Mn-Al-Ni). The most commonly known SMAs are Ni-Ti that are preferable for most applications. The shape memory effect of Ni-Ti SMAs is due to a reversible martensite phase change. Therefore, on heating, the reverse martensitic transformation (MT) results in a single-stage, between martensite (M) and austenite (A) [15]. Under certain conditions, a transformation into two or three-stages is also possible, when an intermediate rhombohedral phase between A and M, called R-phase [16] can be observed. The functional properties and

\footnotetext{
*Corresponding author: bogdan.pricop@academic.tuiasi.ro
} 
transformation temperatures of NiTi SMAs are strongly sensitive to the composition of the alloy. Generally, binary near-equiatomic NiTi SMAs exhibits a thermoelastic MT around room temperature and limits its applications to these temperatures [17]. In addition, in the case of medical applications, a high percentage of $\mathrm{Ni}$ can cause biocompatibility problems due to allergic, toxic and carcinogenic effect that $\mathrm{Ni}$ has [3]. For these reasons, it is necessary to introduce a third alloying element in order to remove these limitations. The mostly used chemical elements are $\mathrm{Ta}$ [18], $\mathrm{Nb}$ [19], $\mathrm{Cu}$ [20], Hf [21], or Fe [22]. For medical applications, a good candidate for Ni substitution is $\mathrm{Ta}$, which in addition to good biocompatibility also gives good visibility during X-ray monitoring. The alloying of Ni-Ti with $\mathrm{Nb}$ leads to a higher thermal hysteresis, which is useful in the case of coupling elements used on an industrial scale [23].

The aim of this paper is to study the influences of the alloying elements, $\mathrm{Nb}$ and $\mathrm{Ta}$, on the thermal behavior of NiTi-based alloys.

\section{Experimental procedure}

In this study, a commercial NiTi alloy with chemical composition $54.5 \mathrm{Ni}-45.5 \mathrm{Ti}$ (m\%) was used as a comparison material. The other two alloys were obtained by induction melting in a graphite crucible, using a high-frequency cold crucible induction furnace. The resulting compositions for the cast alloys were determined using an X-ray fluorescence spectrometer and are shown in Table 1.

Table 1. Chemical composition of NiTiNb and NiTiTa alloys.

\begin{tabular}{|c|c|c|c|c|c|}
\hline \multirow{2}{*}{ Alloy } & \multicolumn{5}{|c|}{ Chemical composition (m\%) } \\
\cline { 2 - 6 } & $\mathbf{N i}$ & $\mathbf{T i}$ & $\mathbf{N b}$ & $\mathbf{T a}$ & Others \\
\hline NiTiNb & 48.21 & 36.91 & 14.62 & - & 0.25 \\
\hline NiTiTa & 47.98 & 36.71 & - & 15.10 & 0.20 \\
\hline
\end{tabular}

The ingots with a diameter of $20 \mathrm{~mm}$ and a height of $48 \mathrm{~mm}$ were longitudinally cut on a spark erosion machine and the obtained rectangular specimens were then subjected to plastic deformation processes by hot rolling at $1073 \mathrm{~K}$ followed by water quenching. This thermomechanical treatment was performed in order to obtain thermally induced martensite as well as a thickness reduction of the specimens. The final thickness after hot rolling was about $1.25 \mathrm{~mm}$. From these lamellas, fragments with a mass of less than $50 \mathrm{mg}$ were cut and cleaned in alcohol in an ultrasonic bath and subjected to differential scanning calorimetry (DSC) analysis. For this purpose, a NETZSCH differential scanning calorimeter type DSC 200 F3 Maya was used, with sensitivity: $<1 \mu \mathrm{W}$, temperature accuracy: $0.1 \mathrm{~K}$ and enthalpy accuracy: generally $<1 \%$. The device was calibrated with $\mathrm{Hg}$, $\mathrm{Bi}$, In, Sn and $\mathrm{Zn}$ standards. The temperature program was: (i) for NiTi sample, heating from room temperature (RT) to $120^{\circ} \mathrm{C}$ followed by cooling to RT; (ii) NiTiNb sample, cooling from RT to $-100^{\circ} \mathrm{C}$, followed by heating to RT and (iii) NiTiTa sample, heating from RT to $200^{\circ} \mathrm{C}$ followed by cooling to RT. All experiments used a heating and cooling rate of $10 \mathrm{~K} / \mathrm{min}$. The measurements were performed under Ar protective atmosphere while the cooling stages used the liquid nitrogen cooling facility of the device. The obtained DSC curves were evaluated with Proteus software using tangent method for the determination of critical transformation temperatures of direct and reverse martensitic transformation. The 
start temperature of the transformation, the temperature where $50 \%$ of the transformation occurred and the end temperature of the transformation were identified and marked with $\mathrm{M}_{\mathrm{s}}, \mathrm{M}_{50}$ and $\mathrm{M}_{\mathrm{f}}$ for direct MT and $\mathrm{A}_{\mathrm{s}}, \mathrm{A}_{50}$ and $\mathrm{A}_{\mathrm{f}}$ for reverse MT. For the determination of specific released/absorbed heat $(\Delta \mathrm{H})$ a linear baseline was used.

\section{Experimental results and discussion}

Figure 1 shows the DSC charts recorded on heating for all investigated alloys. It can be noticed that the samples present a single stage transformation and the endothermic peak is attributed to the reverse MT between monoclinic B19' type crystal structure (martensite M) and cubic B2 type crystal structure (austenite - A) [24, 25, 26, 27]. In the case of NiTi sample, the R-phase transformation was not observed.
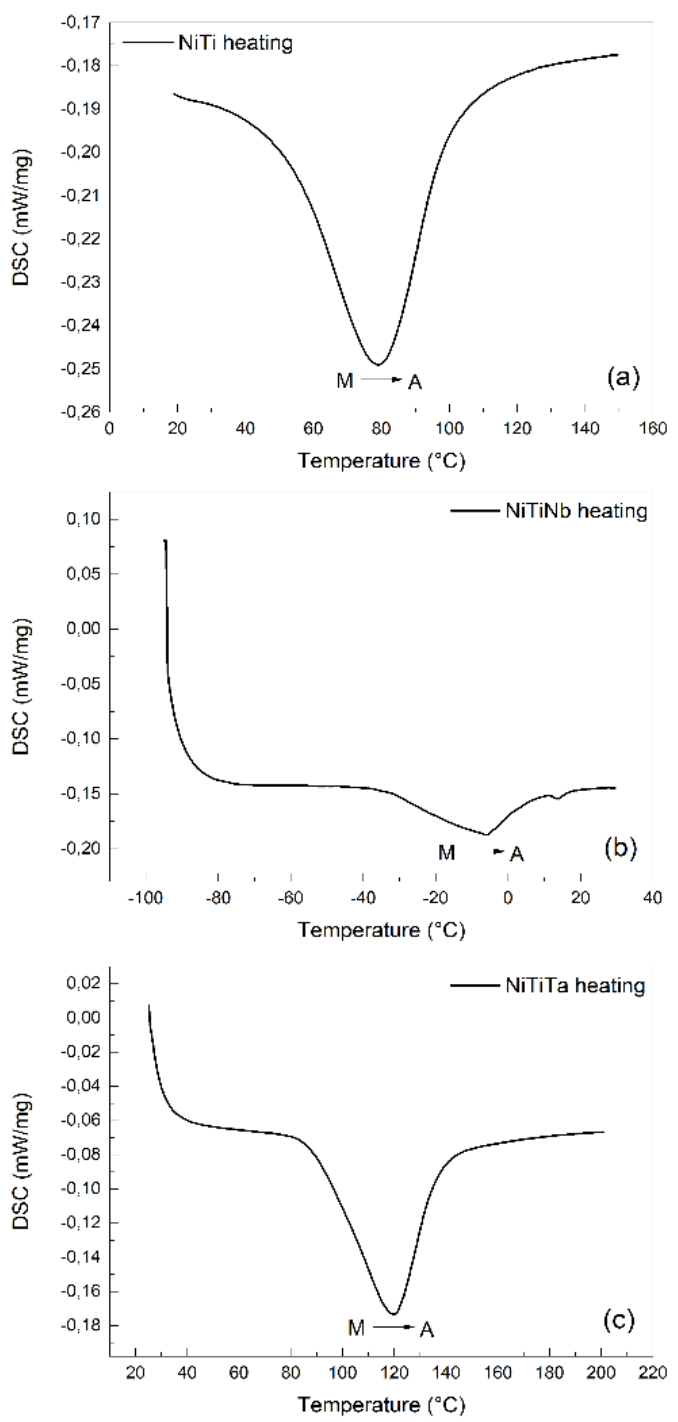

Fig. 1. DSC charts recorded on heating: (a) NiTi, (b) NiTiNb and (c) NiTiTa alloys. 

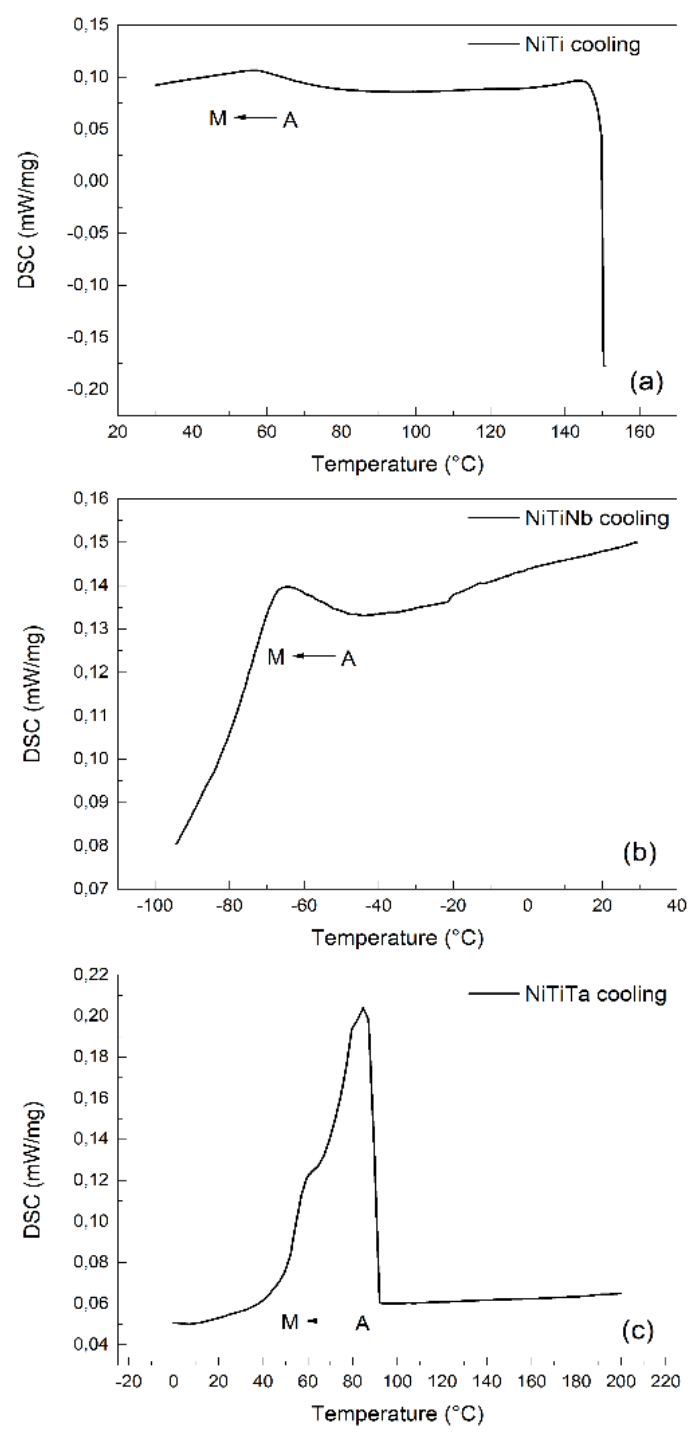

Fig. 2. DSC charts recorded on cooling: (a) NiTi, (b) NiTiNb and (c) NiTiTa alloys.

Figure 2 presents the DSC curves obtained from the cooling process. In this case, one exothermic peak was observed for all samples and was attributed to direct martensitic transformation. Considering that the height of the peak is directly proportional to the transformation speed [28], in the case of NiTi alloy, the speed of the reverse MT is higher than that of direct transformation. The addition of $\mathrm{Nb}$ caused a decrease in the transformation speed for booth inverse and direct MT. This decrease could be attributed to the presence of $\mathrm{Nb}$-rich precipitates, $\beta-\mathrm{Nb}$, which can be found in the NiTi matrix. However, Ta addition had no influence on the transformation speeds.

The critical temperatures and absorbed/released heats of reverse and direct MT are summarized in Table 2. 
Table 2. Summary of critical temperatures and absorbed/released heats for direct and reverse MT. according to the DSC charts from Figure 1 and Figure 2.

\begin{tabular}{|c|c|c|c|c|c|c|c|c|}
\hline \multirow{2}{*}{ Alloy } & $\mathbf{A s}_{\mathbf{s}}$ & $\mathbf{A}_{50}$ & $\mathbf{A}_{\mathbf{f}}$ & $\Delta \mathbf{H} / \mathbf{m}$ & $\mathbf{M}_{\mathbf{s}}$ & $\mathbf{M}_{50}$ & $\mathbf{M}_{\mathbf{f}}$ & $\Delta \mathbf{H} / \mathbf{m}$ \\
\hline & ${ }^{\circ} \mathrm{C}$ & ${ }^{\circ} \mathrm{C}$ & ${ }^{\circ} \mathrm{C}$ & $\mathbf{k J} / \mathbf{k g}$ & ${ }^{\circ} \mathrm{C}$ & ${ }^{\circ} \mathrm{C}$ & ${ }^{\circ} \mathrm{C}$ & $\mathrm{kJ} / \mathrm{kg}$ \\
\hline NiTi & 57,7 & 79,1 & 97,9 & $-4,83$ & 67,8 & 48,3 & 56,5 & 1,30 \\
\hline $\mathrm{NiTiNb}$ & $-31,9$ & $-6,1$ & 5,9 & $-4,74$ & $-52,0$ & $-64,8$ & $-81,1$ & 2,98 \\
\hline NiTiTa & 90,0 & 119,8 & 136,8 & $-19,04$ & 91,0 & 84,0 & 64,1 & 22,65 \\
\hline
\end{tabular}

According to the data from Table 2, it is noticeable that during heating, the endothermic peak recorded for the NiTiNb alloy is shifted to lower temperatures. $\mathrm{A}_{50}$ temperature decreased with $85^{\circ} \mathrm{C}$ and the $\mathrm{M}_{50}$ temperature decreased more than $100^{\circ} \mathrm{C}$. If during the reverse MT of NiTiNb alloy the amount of absorbed heat for the transformation is similar to that of the NiTi alloy, for direct martensitic transformation, the amount of absorbed heat was doubled. Another effect of the addition of Nb element to the binary NiTi SMA is the enhanced phase transformation of the temperature hysteresis. The most popular hypothesis for this increase in hysteresis is that the plastic deformation of $\mathrm{Nb}, \beta-\mathrm{Nb}$-rich precipitates, which is found in this material, leads to the relaxation of the elastic energy stored in the $\mathrm{A} \rightarrow \mathrm{M}$ and $\mathrm{M} \rightarrow \mathrm{A}$ interfaces during the thermo-mechanical treatment [19]. For NiTiTa alloy, the transformation temperatures for MT moved to higher values. In this case, $\mathrm{A}_{50}$ temperature increased with $40^{\circ} \mathrm{C}$ and $\mathrm{M}_{50}$ temperature increased with $10^{\circ} \mathrm{C}$. The absorbed and dissipated heat for the NiTiTa alloy had a value about four times larger for reverse MT and nine times larger for direct MT as compared to NiTi alloy. Therefore, more energy is needed to overcome the hindering of the interface movement in the case of the NiTiTa alloy.

\section{Conclusions}

The influence of $\mathrm{Nb}$ and $\mathrm{Ta}$ alloying elements on the thermal behavior of NiTi shape memory alloys was investigated using DSC analysis. The following variation tendencies were observed:

- the alloying of NiTi binary alloy with $\mathrm{Nb}$ contributed to the modification of the reverse and direct transformation temperatures and their displacement to negative values. Also, the thermal hysteresis increased in the case of this alloy;

- the alloying of NiTi binary alloy with Ta contributed to the increase in the reverse and direct transformation temperatures. In this case, a larger amount of absorbed and released heat has occurred.

\section{References}

1. M.S. Alam, M. Moni, S. Tesfamariam, Eng Struct 34, 8-20 (2012)

2. S.M. Saghaian, H.E. Karaca, H. Tobe, A.S. Turabi, S. Saedi, S.E. Saghaian, Y.I. Chumlyakov, R.D. Noebe, Acta mater 134 211-220 (2017)

3. M.Es-Souni, M.Es-Souni, H. Fischer-Brandies, Anal Bioanal Chem 381, 557-567 (2005).

4. W. Abuzaid, H. Sehitoglu, Scripta Mater 169, 57-60 (2019)

5. T. Sawaguchi, T. Kikuchi, S. Kajiwara, Smart Mater Struct 14 (5) S317 (2015) 
6. T.W. Duerig, D.E. Tolomeo, M. Wholey, Minim Invas Ther 9235 (2000).

7. F. Auricchio, E. Boatti, M. Conti, S.Marconi, Shape Memory Alloy Engineering (Second Edition) Ed: A. Concilio, V. Antonucci, F. Auricchio, L. Lecce, E. Sacco, 627-658 (2021)

8. M.S. Alam, M.A. Youssef, M. Nehdi, Can. J. Civ. Eng. 34 1075-1086 (2007)

9. S. Zareie, A. Salem Issa, R.J. Seethaler, A. Zabihollah, Structure, 27 1535-1550 (2020)

10. S. Viscuso, S. Gualandris, G. de Ceglia, V. Visentin, Shape Memory Alloy Engineering (Second Edition) Ed: A. Concilio, V. Antonucci, F. Auricchio, L. Lecce, E. Sacco, 609-623 (ButterworthHeinemann, 2021)

11. D. Stoeckel, "Engineering Aspects of Shape Memory Alloys" (eds.) T.W. Duerig, K.N. Melton et al 302-307 (1990)

12. A. Riccio, A. Sellitto, S. Ameduri, A. Concilio, M. Arena, Shape Memory Alloy Engineering (Second Edition) Ed: A. Concilio, V. Antonucci, F. Auricchio, L. Lecce, E. Sacco, 785-808 (Butterworth-Heinemann, 2021)

13. M. M. Kheirikhah, S. R Mohammad, E. Edalat, (eds) RoboCup: Robot Soccer World Cup XIV. RoboCup 2010. Lecture Notes in Computer Science, 6556 (2010)

14. V. Malik, S. Srivastava, S. Gupta, V. Sharma, M. Vishnoi, T.G. Mamatha, Materials Today: Proceedings, (2021)

15. S. Kustov, B. Mas, D. Salas, E. Cesari, S. Raufov, V. Nikolaev, J. Van Humbeeck, Scripta Mater 103, 10-13 (2015)

16. K. Otsuka, Engineering Aspects of Shape Memory Alloys, T. W. Duerig, K. N. Melton, D. Stökel, C. M. Wayman (Eds.), (Butterworth-Heinemann, 1990)

17. E. Mohammad Sharifi, A. Kermanpur, F. Karimzadeh, A. Esmaili, J Mater Eng Perform, 23 (4) (2013)

18. N.M. Lohan, B. Pricop, M. Popa, E. Matcovschi, N. Cimpoesu, R. Cimpoesu, B. Istrate, and L.G. Bujoreanu, J Mater Eng Perform 28, 7273-7280 (2019)

19. Y. Wang, S. Jiang, Y. Zhang, Metals-Base 7, 328 (2017)

20. C.J. de Araújo, N.J. da Silva, M.M. da Silva, C.H. Gonzalez, Materials Design, 32, 4925-4930 (2011)

21. M. Pérez-Cerrato, B. Maass, M.L. Nó, J.M. San Juan, J Alloy Compd, 856157948 (2021)

22. S.K.Wu, H.C.Lin, T.Y.Lin, Mat Sci eng A-Struct, 438-440, 536-539 (2006)

23. M. Bitzer, M. Bram, H.P. Buchkremer, D. Stover, J Mater Eng Perform 21(12), 2535-2545 (2012)

24. N. M. Lohan, E. Mihalache, B. Pricop, M.G. Suru, L.G. Bujoreanu, J Optoelectron Adv M, 17(910), $1431(2015)$

25. J. Olbricht, A. Yawny, J. L. Pelegrina, G. Eggeler, V. A. Yardley, J Alloy Compd 579249 (2013)

26. Z.-z. Bao, S. Guo, F. Xiao, X.-q. Zhao, Prog Nat Sci 21(4), 293-300 (2011)

27. C.W. Gong, Y.N. Wang, D.Z. Yang, Mater Chem Phys, 96, 183-187 (2006)

28. M. Wagner, Thermal Analysis in Practice. Fundamental Aspects (Hanser Publications, Cincinnati, 2018) 